\title{
RETRACTED ARTICLE: Solutions to large cases of RSA with transceiver and regeneration allocation (RSAwTCRA) problem in elastic optical networks
}

\author{
Sridhar Iyer ${ }^{1}$
}

Received: 26 January 2017 / Accepted: 12 July 2017 / Published Online: 22 July 2017

(C) Springer Science+Business Media, LLC 2019

The Editor-in-Chief has retracted this article [1] because it shows significant overlap with two previously published articles $[2,3]$. The author does not agree to this retraction.

\section{References}

[1] Iyer, S.: Solutions to large cases of RSA with transceiver and regeneration allocation (RSAwTCRA) problem in elastic optical networks. Photon. Netw. Commun. (2017). https://doi.org/10.1007/s11107-017-0726-8
[2] Klinkowski, M., Żotkiewicz, M., Walkowiak, K., Pióro, M., Ruiz, M., Velasco, L.: Solving large instances of the RSA problem in flexgrid elastic optical networks. J. Opt. Commun. Netw. 8(5), 320-330 (2016)

[3] Klinkowski, M., Walkowiak, K.: On performance gains of flexible regeneration and modulation conversion in translucent elastic optical networks with superchannel transmission. J. Lightwave Technol. 34(23), 5485-5495 (2016)

Electronic supplementary material The online version of this article (https://doi.org/10.1007/s11107-017-0726-8) contains supplementary material, which is available to authorized users.

\section{Sridhar Iyer}

sridhariyer1983@gmail.com

1 Department of ECE, Jain College of Engineering, T.S. Nagar Hunchanatti Cross, Belagavi, Karnataka 590014, India 